\title{
Contribution to diagnostics/prognostics of tuberculosis in children. II. Indicative value of metal ions and biochemical parameters in serum
}

\author{
SVJETLANA LUTEROTTI \\ TONČICA VUKMAN KORDIĆ ${ }^{2}$ \\ IVKA ZORIČIĆ LETOJA ${ }^{3}$ \\ SLAVICA DODIG ${ }^{3}$
${ }^{1}$ Faculty of Pharmacy and HR-10000 Zagreb, Croatia
${ }^{2}$ Agency for Medicinal Products and Medical Devices HR-10000 Zagreb, Croatia
${ }^{3}$ Srebrnjak Children's Hospital \\ Biochemistry, University of Zagreb \\ HR-10000 Zagreb, Croatia
}

Accepted June 15, 2015

\begin{abstract}
Newly introduced methods of assaying simultaneously copper and zinc and zinc alone in serum by flame atomicabsorption spectrometry are simple and economical, especially in saving the consumption of serum material. Along with biochemical parameters, they have been successfully applied to diagnostics/prognostics of tuberculosis in children, through analyses of sera from pediatric patients with lung tuberculosis or suspected tuberculosis, enabling the follow-up of therapeutic efficiency. The prognostic strength of $\mathrm{Cu}$ and $\mathrm{Cu} / \mathrm{Zn}$ ratio together with C-reactive protein, complement components C3 and C4, and erythrocyte sedimentation rate have been documented.
\end{abstract}

Keywords: copper, zinc, $\mathrm{Cu} / \mathrm{Zn}$ ratio, biochemical parameters, children's serum, lung tuberculosis

The role of oligoelements in infections with Mycobacterium tuberculosis is still a question to be answered and therefore still attracting researchers' interest. Iron, copper and zinc play an important role in the immune response to $M$. tuberculosis.

Articles dealing with the status of metal ions in tuberculosis (TBC) patients published recently are scarce. In addition to investigations dealing with adult patients (e.g., refs. 1-6), there are only a few papers dealing with childhood tuberculosis (7-10).

Moraes et al. (1) found lower levels of serum iron, higher copper and $\mathrm{Cu} / \mathrm{Zn}$ ratio but similar zinc in adult TBC patients compared to healthy subjects. They concluded that serum $\mathrm{Cu}$ and $\mathrm{CRP} /$ albumin ratio (CRP - C-reactive protein, an inflammatory response protein) may serve as parameters indicating persistence or recurrence of TBC infection. Cernat and co-workers (2) also found increased $\mathrm{Cu}$ and ceruloplasmin but lowered $\mathrm{Zn}$ in adult patients with active pulmonary tuberculosis. Correlation between serum $\mathrm{Cu}$ and ceruloplasmin was found. These results indicated that $\mathrm{Cu}, \mathrm{Zn}$ and $\mathrm{Cu} / \mathrm{Zn}$ were indirect pointers but not specific markers of TBC. Low concentrations of vitamin A and zinc are common in

\footnotetext{
*Correspondence; e-mail: svjetlana.luterotti@pharma.hr; svjetlana.luterotti@gmail.com
} 
sera of TBC patients. However, Visser et al. (3) detected no effect of supplementation with vitamin A and zinc after an 8-week treatment. Ghulam et al. (4) measured also the significant drop of zinc in serum with advanced age and disease, but the values improved after anti-TBC therapy. Zinc was pointed out as an important tool in diagnostics and monitoring of the response to TBC treatment.

While Nenni and co-workers (7) found that supplementation with zinc, vitamin A and fish oil may be associated with a significant increase in leptin level and significant decrease in tumor necrosis factor alpha (TNF-alpha) in children under anti-TBC therapy, Herlina et al. (8) investigated the association of serum CRP and leptin in TBC patients and found elevated serum CRP and decreased serum leptin associated with an increase in wasting in pediatric TBC. Dodig et al. (9) investigated children with latent tuberculosis infection (LTBI) to see the effects of isoniazid prophylaxis on serum concentrations of high-sensitivity CRP (hsCRP) and complement components C3 and C4. hsCRP was lowered after prophylaxis, showing its usefulness in the follow-up of LTBI patients to evaluate the level of disease power and the response to isoniazid treatment.

Continuing our research devoted to the analysis of metal ions in children's sera (10, 11), we are applying here new analytical methods for copper and zinc (12). Correlations between lung tuberculosis status of children of different age and therapeutic groups with the status of copper and zinc and common biochemical parameters are presented.

\section{EXPERIMENTAL}

\section{Patients and serum samples}

All sera samples were obtained from the Srebrnjak Children's Hospital, Zagreb, Croatia, in 2006 and 2007, and were stored at $-18{ }^{\circ} \mathrm{C}$. All experiments were approved by the Ethical Committees of the Srebrnjak Children's Hospital, Zagreb, Croatia, and Faculty of Pharmacy and Biochemistry, University of Zagreb, Zagreb, Croatia.

The newly established methods were applied to the analyses of remnant children's' sera (age: 1.5 months to 18 years, $N=96,48$ male, 48 female). Upon admittance to the hospital, they were triaged into four groups: TBC group (children with lung tuberculosis, $N=$ 26, age: 1.5 months to 18 years, administered isoniazid, rifampin, pyrazinamide, and ethambutol); LTBI group (children with latent tuberculosis infection, $N=17$, age: 2 to 14 years, isoniazid prophylaxis for 6 months at home); contact group (clinically healthy children who were in contact with a TBC patient, $N=30$, age: 1 to 18 years, CC), controls $(N=23$, age 5 to 18 years, C).

Blood was taken at 8-12 a.m. TBC and LTBI patients' blood was taken at admittance/ starting therapy with isoniazid, rifampin, pyrazinamide and ethambutol or starting prophylaxis with isoniazid, respectively, and for TBC patients, 2-3 times after that during a 3-month follow-up. Time that elapsed between the admittance (group TBC.1) and group TBC. 2 was $7 \pm 4$ weeks (interval 1.5-14 weeks); in addition, 2-4 weeks elapsed before successive measuring of each group, TBC.3 or TBC.4. For LTBI patients, the elapsed time between the admittance (group LTBI.1) and group after prophylaxis (group LTBI.2) was 9 to 11 weeks. 


\section{Metal ions}

Newly established analytical methods were applied for analyses of $\mathrm{Cu}$ and $\mathrm{Zn}$ in children's sera at different dilution levels (12). Cu and Zn were simultaneously determined from 5-fold diluted samples (method A). For analysis of $\mathrm{Zn}$ alone, an additional analytical method involving 10-fold diluted serum samples was suggested (method B). All the experimental details pertaining to analyses of metal ions are described in detail in ref. 12.

\section{Biochemical assays}

Biochemical parameters, immunoglobulins IgG, IgA and IgM, CRP, C3 and C4 were determined by the immunoturbidimetric method on latex particles on a Beckman Coulter AU 400 biochemistry analyzer (Beckman Coulter, Germany), using reagents from the same manufacturer. Erythrocyte sedimentation rate (SE) was assayed using a Vesmatic 20 analyzer (Diesse Diagnostica Senese S. p. A, Italy). Leukocyte (Lkc) and platelet (Plt) counts were determined with a Sysmex XT-1800i analyzer (Sysmex Corporation, Japan). These parameters were used to indicate inflammation in C and CC groups of children. The values were within reference intervals for both age groups ( $0-5$ and $6-18$ years).

\section{Data analysis}

For statistical analyses of the patient data 2-tailed statistical tests at a significance level of 0.05 were applied. These were non-parametric tests (Mann-Whitney U, Kruskal-Wallis and Wilcoxon signed-rank); for normally distributed data Student's $t$-test and F-test were applied.

\section{RESULTS AND DISCUSSION}

Diagnostic outcome and implications in pediatric patients: metal ions and biochemical parameters

Four types of pediatric patients were checked for metal ion status and biochemical parameters: controls, contacts, LTBI and TBC. LTBI and TBC patients were followed during/after therapy/prophylaxis as well (LTBI.1\&LTBI.2, TBC.1 to TBC.4), resulting in a total of 8 experimental groups. Results are presented in Tables I and II and Figs. 1a-d.

$\mathrm{Cu}$ and $\mathrm{Zn}$ assayed simultaneously by method A. - Results are displayed in Table I and Figs. 1a-d. No significant difference was found between age groups ( $0-5$ versus $6-18$ years) for $\mathrm{Cu}, \mathrm{Zn}$ or their ratio in any of the investigated groups (data not shown). Moreover, no significant differences were found between controls and contacts and between controls and LTBI groups for any of the analytes. Also, significant differences were not observed between LTBI.1 and LTBI.2 groups as well as between TBC groups, in any combination.

However, metal ions and the respective $\mathrm{Cu} / \mathrm{Zn}$ ratio differed significantly between the TBC group at admittance (TBC.1) and controls, contacts, LTBI.1 and LTBI.2 (see Figs. 1a-c and Table I) for all patients and for the respective age groups, except for zinc. 


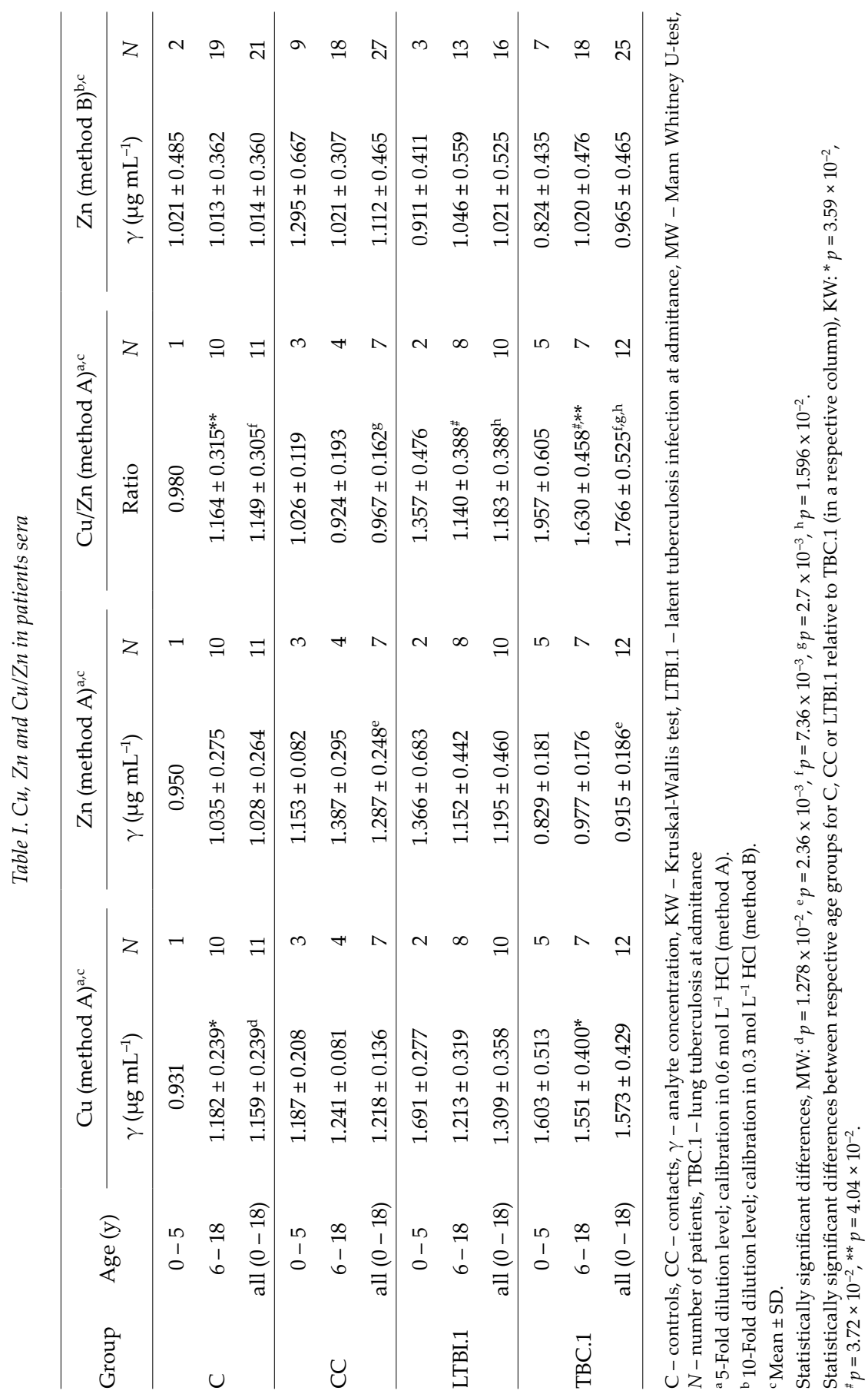


S. Luterotti et al:: Contribution to diagnostics/prognostics of tuberculosis in children. II. Indicative value of metal ions and biochemical parameters in serum, Acta Pharm. 65 (2015) 321-329.

Taking all the age groups into account, serum Cu increased from $1.159 \pm 0.239 \mu \mathrm{g} \mathrm{mL} \mathrm{L}^{-1}$ in the controls $(N=11)$ to $1.573 \pm 0.429 \mu \mathrm{g} \mathrm{mL} \mathrm{L}^{-1}$ in TBC children $(N=12)$ but returned to $1.187 \pm 0.075 \mu \mathrm{g} \mathrm{mL}^{-1}(N=4)$ after 3-month treatment. At the same time, $\mathrm{Zn}$ decreased from $1.028 \pm 0.264 \mu \mathrm{g} \mathrm{mL}^{-1}$ in controls $(N=11)$ to $0.915 \pm 0.186 \mu \mathrm{g} \mathrm{mL} \mathrm{L}^{-1}$ in TBC patients $(N=12)$ and increased again in the last measurement to $1.114 \pm 0.138 \mu \mathrm{g} \mathrm{mL}^{-1}(N=4)$. Since serum $\mathrm{Cu}$ concentration significantly increased $\left(p=1.278 \times 10^{-2}\right)$ and that of $\mathrm{Zn}$ simultaneously decreased in patients with TBC, $\mathrm{Cu} / \mathrm{Zn}$ ratio increased significantly as well $\left(p=7.36 \times 10^{-3}\right)$ in TBC patients, but returned to normal values in LTBI and contact persons, and in TBC persons within 3 months of therapy/prophylaxis (Fig. 1c). Interesting to note, the first strong increase of $\mathrm{Cu} / \mathrm{Zn}$ ratio from $1.149 \pm 0.305(N=11)$ in controls to $1.766 \pm 0.525(N=12)$ in TBC.1 group came back to $1.081 \pm 0.185(N=4)$ after commencing the therapy. Analogous trends were observed for all age groups.

The scatter of data within each group for both metal ions in all patient groups (Table I) ranged from $10-27 \%$ for $\mathrm{Cu}$ and $11-39 \%$ for $\mathrm{Zn}$, and $17-33 \%$ for the ratio. This seems to be a result of both method's intermediate imprecision (about $13 \%$ for both analytes, see ref. 12) but dominantly of high between-patient variability. Such a variability amounting $10-40 \%$ for both metals made the recognition of significant differences difficult. In line with this, no significant difference for any metal ion or its ratio, before and during/after therapy/prophylaxis, was found.

Zn by method B. - Fig. 1d illustrates zinc levels in patients' sera after 10-fold dilution; no significant differences were observed between any of the groups. No differences were observed between the age groups either (Table I). One of the possible reasons might be the high variability for $\mathrm{Zn}$ at $10 \times$ dilution level, which ranged from 14 to $53 \%$ within patient groups.

$\mathrm{Zn}$ values obtained from paired data sets of TBC children $(N=12)$, namely before commencing and during/after the therapy (within 3 months), were $0.871 \pm 0.373$ and 1.016 $\pm 0.345 \mu \mathrm{g} \mathrm{mL}^{-1}$, showing a slight still not significant return of $\mathrm{Zn}$ level. An opposite trend was observed after prophylaxis in LTBI groups $(0.999 \pm 0.686$ at admittance, followed by $0.842 \pm 0.192 \mu \mathrm{g} \mathrm{mL} \mathrm{L}^{-1}$ after prophylaxis, $N=6$ ).

Results for $\mathrm{Zn}$ when taken all together, show an average return of the value for ca 10 $\%$ after commencing the therapy.

Concentrations of both metal ions and their ratio in sera of C and CC groups of children comply with the physiological values for general child population $(13,14)$.

Biochemical parameters. - Measured biochemical parameters are presented in Table II. The values for IgG, IgA, IgM, SE, Lkc, and Plt found in samples of $C$ and CC children agree well with physiological values (15).

Significant differences for IgG and IgA were found between age groups in contacts, LTBI.1 and TBC.1 groups (see Table II).

Correlations found between biochemical parameters and metal ions are given in Table II. In the TBC.1 group, $R \geq 0.7$ was found between $\mathrm{Cu}$ and IgA, CRP, C3, C4 and SE, and similarly in the LTBI.1 group between $\mathrm{Cu}$ and IgM, C3, C4 and SE. CRP, C3 and C4 were found to be significantly higher in TBC.1 and LTBI.1 than in controls and/or contacts. These results reveal that $\mathrm{Cu}$ is involved in both, severe lung inflammations in patients with TBC and in latent inflammations in patients with LTBI. In TBC patients, severe inflammation is mediated by IgA, CRP, C3, and C4, while in LTBI patients, latent inflammation is mediated by IgM, C3 and C4. Involvement of a complement system was confirmed in both processes. 

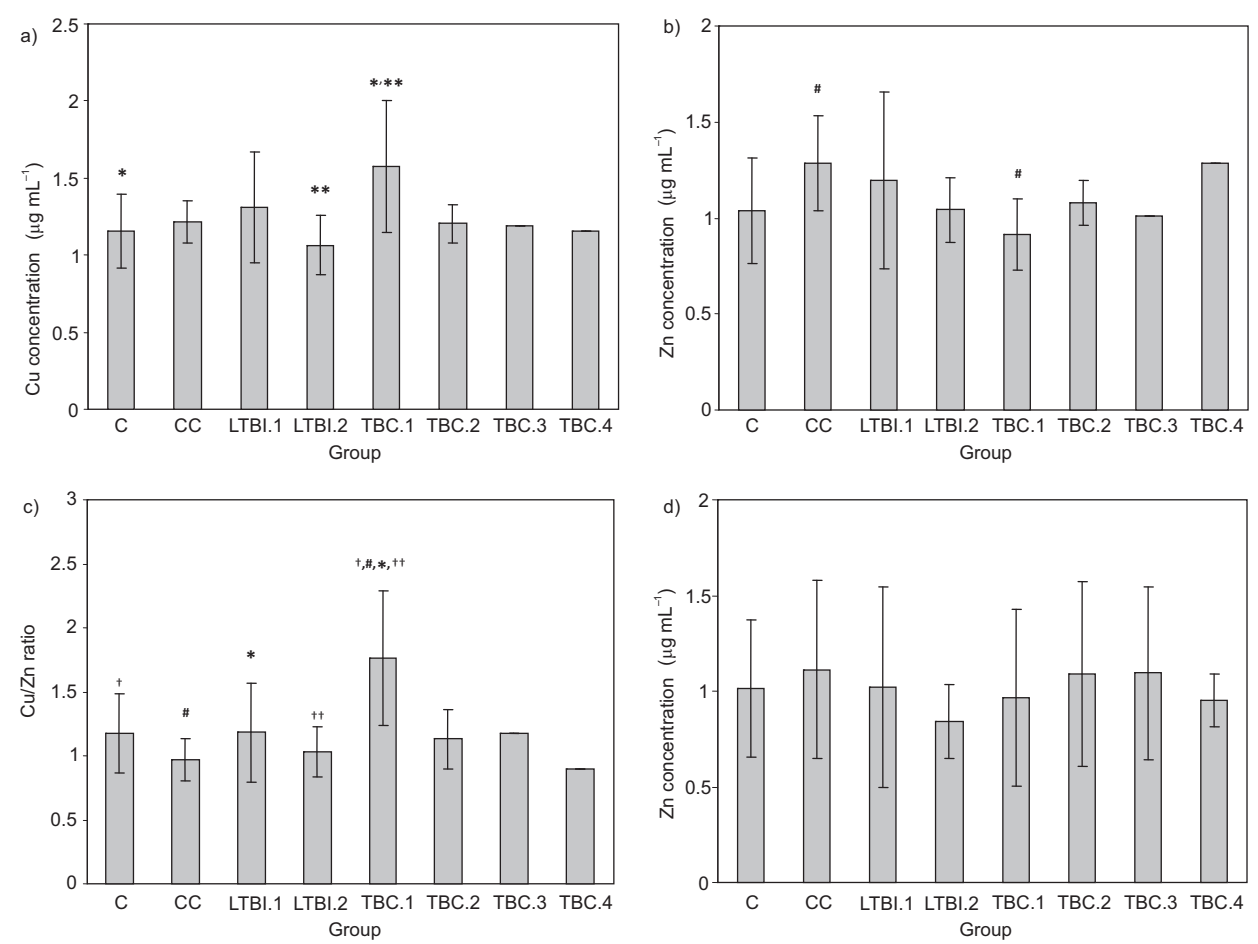

Fig. 1a-d. Analyses of serum samples at 5-fold dilution level: a) copper, b) zinc and c) $\mathrm{Cu} / \mathrm{Zn}$ ratio; at 10 -fold dilution level: $\mathrm{d}$ ) zinc. Mean $\pm \mathrm{SD}$, for number of patients $(N)$ see Table I.

Significant differences (Mann-Whitney U-test): ${ }^{*} p<0.005,{ }^{t,+t} p<0.01,{ }^{* * * *} p<0.05$. C - controls, CC contacts, CRP - C-reactive protein, C3, C4 - complement components C3 and C4, IgG, IgA, IgM - immunoglobulins G, A and M, Lkc - leukocyte, LTBI.1 - latent tuberculosis infection, at admittance, LTBI. 2 - latent tuberculosis infection after prophylaxis, Plt - platelets, TBC.1 - lung tuberculosis at admittance, TBC.2, TBC.3, TBC.4 - lung tuberculosis after/during therapy up to 3 months.

In TBC.1, leukocytes and platelets were also significantly higher than in C and CC. All these values levelled off during therapy.

No significant differences, except for CRP, were observed between biochemical parameters during/after therapy/prophylaxis for up to 3 months. CRP differed significantly between TBC.1 and TBC. 2 groups paired data (Wilcoxon signed-rank test, 11 pairs of data, $\left.p=3.662 \times 10^{-2}\right)$.

\section{Prognostic/diagnostic applicability of metal ions and biochemical parameters}

The data given in Table II connects Cu with CRP, C3, C4 and SE in a set of values, which might represent a general indicator of lung tuberculosis status in children. This partly agrees with the findings of Moraes et al. (1) and Cernat and co-workers (2). Our findings also demonstrate the usefulness of $\mathrm{Cu} / \mathrm{Zn}$ ratio, similarly to Cernat et al. (2) who indicated that $\mathrm{Cu}, \mathrm{Zn}$ and $\mathrm{Cu} / \mathrm{Zn}$ might be considered indirect pointers but not specific mark- 


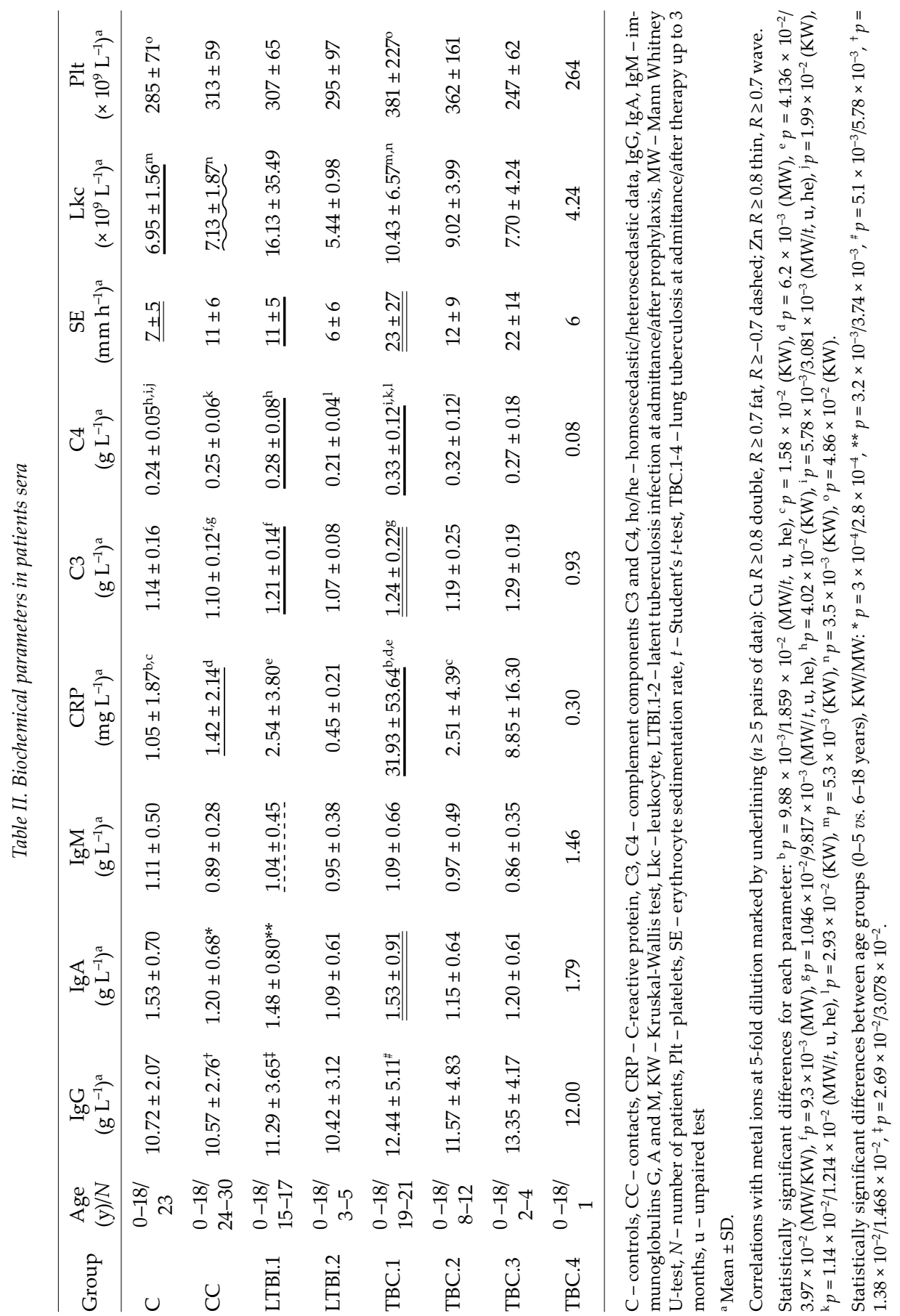


ers of TBC. Contrary to Ghulam et al. (4), who pointed out $\mathrm{Zn}$ as a an important tool in diagnostics and monitoring of the response to TBC treatment, our findings do not support the idea of the usefulness of zinc level as a good marker in TBC diagnostics/prognostics in children. Dodig et al. (9) showed that high-sensitivity CRP, C3 and C4 significantly increased in LTBI and TBC children, the former showing pre-therapy - post-therapy changes, thus being applicable in TBC follow-up. Our findings partly coincide with that of Dodig et al. (9): CRP, C3 and C4 returned to lower values after therapy/prophylaxis. The main limitation of the present study is the lack of an interferon gamma release assay to diagnose LTBI (16).

\section{CONCLUSIONS}

New analytical methods for $\mathrm{Cu}$ and $\mathrm{Zn}$ were found fully applicable to simultaneous determination of $\mathrm{Cu}$ and $\mathrm{Zn}$ and $\mathrm{Zn}$ alone in sera of healthy children and those with tuberculosis infection or suspected TBC. $\mathrm{Cu} / \mathrm{Zn}$ ratio, along with the set of data including $\mathrm{Cu}, \mathrm{CRP}, \mathrm{C} 3, \mathrm{C} 4$ and SE, have proven useful as reliable prognostic/diagnostic tools when solving pediatric tuberculosis problems. More detailed investigations (including determination of LTBI by an interferon gamma release assay) are needed to clearly define the biomarkers that will unequivocally evaluate the level of disease and the response to the treatment.

\section{REFERENCES}

1. M. L. Moraes, D. M. Ramalho, K. N. Delogo, P. F. Miranda, E. D. Mesquita, H. M. De Melo Guedes de Oliveira, A. R. Netto, M. J. Dos Anjos, A. L. Kritski and M. M. De Oliveira, Association of serum levels of iron, copper, and zinc, and inflammatory markers with bacteriological sputum conversion during tuberculosis treatment, Biol. Trace Elem. Res. 160 (2014) 176-184; DOI: 10.1007/s12011014-0046-0.

2. R. I. Cernat, T. Mihaescu, M. Vornicu, D. Vione, R. I. Olariu and C. Arsene, Serum trace metal and ceruloplasmin variability in individuals treated for pulmonary tuberculosis, Int. J. Tuberc. Lung Dis. 15 (2011) 1239-1245; DOI: 10.5588/ijtld.10.0445.

3. M. E. Visser, H. M. Grewal, E. C. Swart, M. A. Dhansay, G. Walzl, S. Swanewelder, C. Lombard and G. Maartens, The effect of vitamin A and zinc supplementation on treatment outcomes in pulmonary tuberculosis: a randomized controlled trial, Am. J. Clin. Nutr. 93 (2011) 93-100; DOI: 10.3945/ajcn.110.001784.

4. H. Ghulam, S. M. Kadri, A. Manzoor, Q. Waseem, M. S. Aatif, G. Q. Khan and K. Manish, Status of zinc in pulmonary tuberculosis, J. Infect. Dev. Ctries 3 (2009) 365-368.

5. J. D. Bogden, D. I. Lintz, M. M. Joselow, J. Charles and J. S. Salaki, Copper/zinc ratios in whole blood, plasma and erythrocytes in pulmonary tuberculosis, Health Lab. Sci. 15 (1978) 38-44.

6. T. U. Ciftci, B. Ciftci, O. Yis, Y. Guney, A. Bilgihan and M. Ogretensoy, Changes in serum selenium, copper, zinc levels and $\mathrm{Cu} / \mathrm{Zn}$ ratio in patients with pulmonary tuberculosis during therapy, Biol. Trace Elem. Res. 95 (2003) 65-71.

7. V. Nenni, H. M. Nataprawira and T. Yuniati, Role of combined zinc, vitamin A, and fish oil supplementation in childhood tuberculosis, Southeast Asian J. Trop. Med. Public Health 44 (2013) 854-861.

8. M. Herlina, H. M. Nataprawira and H. Garna, Association of serum C-reactive protein and leptin levels with wasting in childhood tuberculosis, Singapore Med. J. 52 (2011) 446-450. 
9. S. Dodig, D. Galez, I. Zoričić-Letoja, B. Kristić-Kirin, K. Kovač, B. Nogalo, J. Živčić and R. ZrinskiTopić, C-reactive protein and complement components C3 and C4 in children with latent tuberculosis infection, Biochem. Med. 18 (2008) 52-58.

10. S. Luterotti and T. Vukman, Acidic method for determination of copper in blood serum by FAAS, Acta Pharm. 52 (2002) 143-148.

11. S. Luterotti, T. Vukman Kordić and S. Dodig, Simultaneous determination of iron and copper in children's sera by FAAS, Acta Pharm. 61 (2011) 93-102; DOI: 10.2478/v10007-011-008-4.

12. S. Luterotti, T. Vukman Kordić and S. Dodig, Contribution to diagnostics/prognostics of tuberculosis in children. I. New methods of assaying zinc and simultaneously copper and zinc in diluted sera by FAAS, Acta Pharm. 65 (2015) 311-320; DOI: 10.1515/acph-2015-00226.

13. Z. Flegar-Meštrić, N. Jagarinec, B. Šurina, D. Vrhovski-Hebrang, V. Preden-Kereković, S. Perkov and B. Smuđ-Makalouš, Reference intervals for biochemistry analytes determined in the sera of children and adolescents from Zagreb, Croatia, Biochem. Med. 6 (1996) 277-288.

14. G. Lockitch, A. C. Halstead, L. Wadsworth, G. Quigley, L. Reston and B. Jacobson, Age- and sexspecific pediatric reference intervals and correlations for zinc, copper, selenium, iron, vitamins A and E, and related proteins, Clin. Chem. 34 (1988) 1625-1628.

15. E. Topić, Z. Flegar-Meštrić, D. Batinić and D. Čvorišćec (Eds.), Harmonisation of Laboratory Findings in the Field of Common, Specific and Subspecific Clinical Chemistry, Croatian Chamber of Medical Biochemists, Medicinska naklada, Zagreb 2007.

16. I. Pavić, R. Zrinski Topić, M. Raos, N. Aberle and S. Dodig, Interferon- $\gamma$ release assay for the diagnosis of latent tuberculosis in children younger than 5 years of age, Pediatr. Infect. Dis. J. 30 (2011) 866-870; DOI: 10.1097/INF.0b013e318220c52a. 